\title{
Archéologie du moi, textes réunis par Gisèle Berkman et Caroline Jacot Grapa
}

Gabriella Bosco

\section{(2) OpenEdition}

1 Journals

\section{Edizione digitale}

URL: http://journals.openedition.org/studifrancesi/7090

DOI: $10.4000 /$ studifrancesi.7090

ISSN: 2421-5856

\section{Editore}

Rosenberg \& Sellier

\section{Edizione cartacea}

Data di pubblicazione: 1 septembre 2010

Paginazione: 425-426

ISSN: 0039-2944

\section{Notizia bibliografica digitale}

Gabriella Bosco, «Archéologie du moi, textes réunis par Gisèle Berkman et Caroline Jacot Grapa», Studi Francesi [Online], 161 (LIV | II) | 2010, online dal 30 novembre 2015, consultato il 09 janvier 2021. URL: http://journals.openedition.org/studifrancesi/7090 ; DOI: https://doi.org/10.4000/studifrancesi.7090

Questo documento è stato generato automaticamente il 9 janvier 2021.

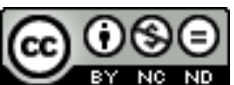

Studi Francesi è distribuita con Licenza Creative Commons Attribuzione - Non commerciale - Non opere derivate 4.0 Internazionale. 


\title{
Archéologie du moi, textes réunis par Gisèle Berkman et Caroline Jacot Grapa
}

\author{
Gabriella Bosco
}

\section{NOTIZIA}

AA.VV., Archéologie du moi, textes réunis par Gisèle BERKMAN et Caroline JACOT GRAPA, SaintDenis, Presses Universitaires de Vincennes, 2009, «La Philosophie hors de soi», pp. 236.

1 Atti del convegno organizzato il 29 e 30 novembre 2007 alla Bibliothèque des Cerclades dell'Université de Cergy-Pontoise, il volume indaga - dall'Antichità latina ai Lumi e dai Lumi alla modernità - $\mathrm{i}$ contorni di una figura a tratti labile ma persistente persino nell'era della "morte dell'autore": il moi.

2 Alla luce, e sollecitati da quella che opportunamente le curatrici chiamano nella loro introduzione "la querelle du Sujet" sviluppatasi nella seconda metà del xx secolo (Gisèle BERKMAN et Caroline JACOT GRAPA, Questions pour une archéologie du moi, pp. 5-20), gli autori dei contributi raccolti nel volume ricostruiscono le alterne vicende di una nozione la cui prima incertezza è di natura lessicale. Da un'epoca all'altra e da una lingua all'altra, il pronome è stato sostituito, scavato, investito, svuotato, rilegittimizzato, abolito e ripreso: a testimonianza della sua problematicità, ma insieme della sua forza.

Tre le sezioni che strutturano il discorso: partendo dal clivage tra il moi seicentesco e quello settecentesco, che per convenzione - a partire soprattutto dagli studi sul genere autobiografico di Philippe Lejeune - si suole considerare inaugurale di una concezione moderna del soggetto, per poi passare alla riflessione filosofica sulla nozione, e infine approdare agli esiti novecenteschi, quindi i più diversi e aperti, della stessa, a cavallo tra principio d'identità e esigenza di depersonalizzazione.

4 La prima parte è intitolata «Scènes du moi» e comprende gli interventi di Liliane PICciolA consacrato a Corneille (La quête de soi sur la scène cornélienne: $d u$ «moi» éclatant au 
«moi» éclaté, pp. 23-40); di Sabine CHAOUche su Diderot («Cachez ce Moi que je ne saurais voir...». De la philosophie de l'art théâtral à la philosophie de l'esprit: la subjectivité de l'acteur chez Diderot, pp. 41-60); di Frédéric LE BLAY sulla lettera vista come luogo di esplorazione del moi attraverso il prisma del pensiero stoico e le sue influenze, da Montaigne a Rousseau (Aux origines de l'individu: esquisses antiques, pp. 61-82); di Rudy LE MENTHÉOUR sul moi delle Confessions e il superamento dei presupposti classici della conoscenza di sé tramite la sintesi tra interiorità e antropologia (Rousseau, médecin du moi, pp. 83-94); e quello di Etienne BEAULIEU su Benjamin Constant e la tensione paradossale che si delinea nella sua opera tra soggetto privato e soggetto pubblico (La souveraine indifférence de Benjamin Constant, pp. 95-108).

La seconda sezione, «Sciences du moi», prende in esame il moi non più in termini di rappresentazione, bensì di elaborazione teorica in diversi ambiti: psicologia, antropologia filosofica, psicanalisi. Anne DURAND studia La critique du Moi dans la philosophie de Lud-wig Feuerbach (pp. 111-126). Sandra JENSSEN si occupa della comparsa, nella modernità, dell'interrelazione tra psicologico e sociale (Figures d'une subjectivité négative, 1850-1950, pp. 127-141). Madeleine MICHEAU illustra l'elaborazione clinica della nozione di moi in Freud (Le moi dans la théorie freudienne, pp. 143-152). Concludono Daniel DERIVOIS, Ming-Sung KIM e Ludovic ISSARTEL che presentano i risultati di un'indagine sociologica condotta sul campo da cui risulta che il moi è una costruzione occidentale (Vers un moi interculturel: trajectoires $d u$ Moi en situation migratoire et interculturelle, pp. 153-161).

6 La terza parte, «Moi de papier», raccoglie interventi che analizzano rappresentazioni varie del soggetto, dal surrealismo a oggi. Patrick POGNANT studia una particolare forma di soggettivazione erotica in René Crevel ("Mon corps et moi" de René Crevel. Le roman d'une impossible conciliation, pp. 165-180). Sylvie SANTI individua una sorta di processo del moi intentato da Henri Michaux (Face au "Plume" de Michaux: penser son moi, pp. 181196). L'ipotesi di un "ritorno" dell'autore nel romanzo d'inizio xxi secolo è avanzata da Sylvie DUCAS (Archéologie du moi et fable auctoriale dans les fictions contemporaines: un espace d'invention, pp. 197-210). Mentre Florian PENNANECH chiude il volume con Roland Barthes, al centro della "querelle du sujet" e malgrado ciò, a suo avviso, riscopritore da un certo punto in poi di un Moi, ingannevole ma salutare (L'œeuvre-sujet chez Roland Barthes, pp. 211-224). 